\title{
HAART in hand: The change in Kaposi's sarcoma presentation in KwaZulu-Natal, South Africa
}

\author{
L Naidoo, ${ }^{1} \mathrm{MB}$ ChB, FCDerm (SA); J S Jacobson, ${ }^{2}$ DrPH, MPH, MBA, BA; A I Neugut ${ }^{2}$ MPH, PhD, MD, BA; \\ N C Dlova, ${ }^{1}$ MB ChB, FCDerm (SA), PhD; A Mosam, ${ }^{1}$ MB ChB, FCDerm (SA), MMed, PhD \\ ${ }^{1}$ Department of Dermatology, School of Clinical Medicine, College of Health Sciences, Nelson R Mandela School of Medicine, \\ University of KwaZulu-Natal, Durban, South Africa \\ ${ }^{2}$ Department of Epidemiology, Mailman School of Public Health, Columbia University, New York, USA
}

Corresponding author: L Naidoo (levashni.naidoo@yahoo.com)

\begin{abstract}
Background. HIV/AIDS-related Kaposi's sarcoma (HIV-KS) is a public health problem in South Africa (SA). It is AIDS defining. There have been no studies evaluating its prevalence since the national roll-out of highly active antiretroviral therapy (HAART).

Objective. To evaluate the effect of HAART on the disease profile of HIV-KS in KwaZulu-Natal Province (KZN), SA.

Methods. Charts of patients with histologically confirmed HIV-KS were reviewed at an oncology clinic in KZN. The significance of associations of HAART with age, gender, CD4 count, urban/rural residence, fungating lesions, ulceration and lymphoedema, and treatment delay, was determined by $t$-tests for normally distributed continuous variables and $\chi^{2}$ tests for categorical variables. Logistic regression models were used to analyse the association of HAART with CD4 count.

Results. Of 198 patients, 194 were documented as HIV-positive; 168 (86.6\%) were on HAART at the time of their KS diagnosis. The mean CD4 count of 266 cells $/ \mu \mathrm{L}$ was higher than that in previous studies at this site. The mean age at presentation was 36.6 (standard deviation $10.1)$ years. Females presented at a younger mean age than males $(p<0.001)$. The mean age of females on HAART was 34.7 years and that of males 39.0 years $(p=0.003)$. HAART-naive patients were three times more likely than those receiving HAART $(15.4 \%$ v. $4.8 \%)$ to have visceral involvement $(p=0.03)$.

Conclusions. HAART use has resulted in outcome improvement. Mean age at presentation has increased in the group as a whole and for females in particular. The trend in mean CD4 counts has shown positive growth. Females no longer shoulder a disproportionate burden of disease.
\end{abstract}

S Afr Med J 2016;106(6):611-616. DOI:10.7196/SAMJ.2016.v106i6.10333

Kaposi's sarcoma (KS) has played a pivotal role in medical history as one of the two diseases in which an unexpected cluster led to the identification of HIV/AIDS. ${ }^{[1]}$ It is a tumour of the blood and lymphatic vessels caused by the infectious agent human herpesvirus 8 (HHV8 or Kaposi's sarcoma virus). All four of its subtypes typically involve cutaneous lesions, and may additionally affect the oral cavity, lymph nodes and viscera. Compared with the other three subtypes (classic KS, African endemic KS and immunosuppression-related KS), HIV/AIDS-related KS (HIV-KS) is more aggressive, more likely to involve the lymph nodes, and more lethal. ${ }^{[2,3]}$

Antiretroviral therapy in the Western world, irrespective of the specific regimen, has been found to improve HIV-KS outcomes. ${ }^{[4]}$ Highly active antiretroviral therapy (HAART), a further advance in treatment, has also led to improvement in HIV-KS outcomes. ${ }^{[5,6]}$ HAART has notably been associated with a decrease in the incidence of HIV-KS, ${ }^{[5]}$ protection against KS, ${ }^{[6]}$ a longer time to tumour progression, ${ }^{[7]}$ and improvement in both prognosis and survival. ${ }^{[8]}$

The national roll-out of HAART in South Africa (SA) did not begin until 2003. The most recent studies of HIV-KS characteristics and incidence in SA were conducted in the pre-HAART and early HAART period, ${ }^{[2,9,10]}$ during which KwaZulu-Natal (KZN), a province of SA (population 10 million, capital city Durban), emerged as the epicentre of both HIV/AIDS and KS prevalence in Africa and the world. Now that the incidence of HIV/AIDS has levelled off and increasing numbers of HIV-positive patients are using HAART, it seemed timely to evaluate the effects of these changes in a sample of HIV-KS patients in KZN.

\section{Methods}

\section{Study design and sample population}

A retrospective chart analysis was performed at the oncology clinic at Addington Hospital (ADH), a 571-bed district- and regionallevel hospital in Durban, KZN. This site was selected because it is the oncology clinic to which HIV-KS patients in KZN are referred. Previous HIV-KS studies have also been conducted at this site, and its selection facilitated temporal comparisons.

Patients diagnosed with HIV-KS in 2011 had greater opportunities to be treated with HAART than those diagnosed in earlier years. We, therefore, restricted our sample to HIV-KS patients who first presented to the oncology clinic in 2011. We excluded patients whose charts lacked documentation/confirmation of HIV status or histological confirmation of KS, patients with KS unrelated to HIV/ AIDS, patients with more than one diagnosis of cancer, and patients who were not chemotherapy or radiotherapy naïve.

Ethical approval for the study was obtained from the institutional review board of the Nelson R Mandela School of Medicine, University of KwaZulu-Natal (Ref. BE338/14).

\section{Definitions}

A case of HIV-KS was defined as a patient diagnosed with HIV in whom histological confirmation of KS had been made. HIV-KS stage was based on the modified AIDS Clinical Trial Group (ACTG) guidelines. ${ }^{[11]}$ Patients were categorised as at poor risk if they had visceral disease, lymphoedema or ulceration (T1), advanced immune suppression (CD4 count $<150$ cells $/ \mu \mathrm{L}$ ) (I1), or systemic features of AIDS such as a history of opportunistic infections (S1). Patients were 
categorised as at good risk if they met none of those criteria.

\section{Data collection, methods and tools}

On request, the principal specialist who ran the oncology clinic at $\mathrm{ADH}$ gave permission to access the patient charts. Data were collected manually at the clinic because KZN does not have a cancer registry and the oncology clinic lacks a computerised database of patients.

The following were captured from patient charts: demographic characteristics (age, gender, race, and urban or rural residence), immunological status (CD4 count), clinical findings (opportunistic infections and the staging-related conditions listed above), and proposed initial management (HAART, chemotherapy, radiotherapy).

\section{Statistical analysis}

On charts that yielded the full complement of data, we compared patients receiving and not receiving HAART with regard to demographic, clinical and immunological characteristics. Patients from urban areas were also compared with those from rural areas with regard to age, clinical presentation, tumour stage and CD4 count. To evaluate the statistical significance of univariate associations, we used $t$-tests for normally distributed continuous variables and $\chi^{2}$ tests for categorical variables. Continuous variables that were not normally distributed were categorised as quartiles for analysis We developed logistic regression models to analyse the association of HAART with CD4 count, urban/rural residence, fungating lesions, ulceration and lymphoedema, and treatment delay, controlling for age and sex. We also analysed the association of clinical presentation with gender. For the logistic regression models, statistical significance was assessed on the basis of the $95 \%$ confidence intervals (CIs) around the odds ratios (ORs).

\section{Results}

All the 198 charts with a diagnosis of KS documented the HIV status of the patients; only four were HIV-negative. Of the 194 HIV-positive patients, 168 (86.6\%) were on HAART at the time of their first presentation to the oncology clinic.

Of the total sample, 183 had poor-risk disease, 4 had good-risk disease, and 7 could not be staged from the records in the clinical charts.

Of the 136 patients whose charts included the date of histological examination, 79 (58.1\%) presented within 3 months of KS diagnosis (Table 1), including 64 of 117 patients on HAART (54.7\%) and 15 of 19 not on HAART
Table 1. Patient demographic and clinical characteristics according to HAART status

\begin{tabular}{|c|c|c|c|c|}
\hline & $\begin{array}{l}\text { HAART }(N=168, \\
86.6 \%), n(\%)\end{array}$ & $\begin{array}{l}\text { No HAART }(N=26 \text {, } \\
13.4 \%), n(\%)\end{array}$ & $\begin{array}{l}\text { Total }(N=194, \\
100.0 \%), n(\%)\end{array}$ & $p$-value \\
\hline Age quartiles (years) & & & & 0.03 \\
\hline $2-29$ & $36(21.4)$ & $12(46.2)$ & $48(24.7)$ & \\
\hline $30-35$ & $41(24.4)$ & $4(15.4)$ & $45(23.2)$ & \\
\hline $36-41$ & $50(29.8)$ & $3(11.5)$ & $53(27.3)$ & \\
\hline $42-81$ & $41(24.4)$ & $7(26.9)$ & $48(24.7)$ & \\
\hline Gender & & & & 0.40 \\
\hline Male & $92(54.8)$ & $17(65.4)$ & $109(56.2)$ & \\
\hline Female & $76(45.2)$ & $9(34.6)$ & $85(43.8)$ & \\
\hline Race & & & & 1.00 \\
\hline Black & $167(99.4)$ & $26(100.0)$ & $193(99.5)$ & \\
\hline Coloured & $1(0.6)$ & $0(0.0)$ & $1(0.5)$ & \\
\hline Residence & & & & 0.07 \\
\hline Urban & $96(57.1)$ & $21(80.8)$ & $117(60.3)$ & \\
\hline Rural & $71(42.3)$ & $5(19.2)$ & $76(39.2)$ & \\
\hline Unknown & $1(0.6)$ & $0(0.0)$ & $1(0.5)$ & \\
\hline Opportunistic & & & & 0.02 \\
\hline
\end{tabular}

infections

$\begin{array}{llll}\text { Tuberculosis } & 20(11.9) & 0(0.0) & 20(10.3) \\ \text { Oral Candida } & 0(0.0) & 1(3.8) & 1(0.5) \\ \text { Both } & 3(1.8) & 1(3.8) & 4(2.1) \\ \text { Unknown } & 145(86.3) & 24(92.3) & 169(87.1) \\ \text { Skin lesions } & & & \\ \text { None } & 12(7.1) & 3(11.5) & 15(7.7) \\ \text { Localised } & 92(54.8) & 15(57.7) & 107(55.2) \\ >1 \text { skin site } & 60(35.7) & 7(26.9) & 67(34.5) \\ \text { Unknown } & 4(2.4) & 1(3.8) & 5(2.6)\end{array}$

Oral lesions

Yes

$11(42.3)$

15 (57.7)

0.02

No

43 (25.6)

$125(74.4)$

Visceral lesions

Yes $8(4.8)$

4 (15.4)

$21(80.8)$

No $159(94.6)$

Unknown $\quad 1(0.6)$

1 (3.8)

Lymphoedema

Yes

80 (47.6)

$11(42.3)$

No $\quad 85(50.6)$

$15(57.7)$

$0(0.0)$

0.57

Unknown

2 (1.2)

Fungating lesions

Yes $23(13.7)$

5 (19.2)

No $142(84.5)$

$21(80.8)$

Unknown

$3(1.8)$

$0(0.0)$

Ulceration

$\begin{array}{lll}\text { Yes } & 8(4.8) & 1(3.8) \\ \text { No } & 159(94.6) & 24(92.3) \\ \text { Unknown } & 1(0.6) & 1(3.8)\end{array}$

54 (27.8)

$140(72.2)$

$180(92.8)$

0.31

0.10

0.03

$91(46.9)$

$100(51.5)$

2 (1.0)

28 (14.4)

$163(84.0)$

3 (1.5)

9 (4.6)

$183(94.3)$

2 (1.0) 
Table 1. (continued) Patient demographic and clinical characteristics according to HAART status

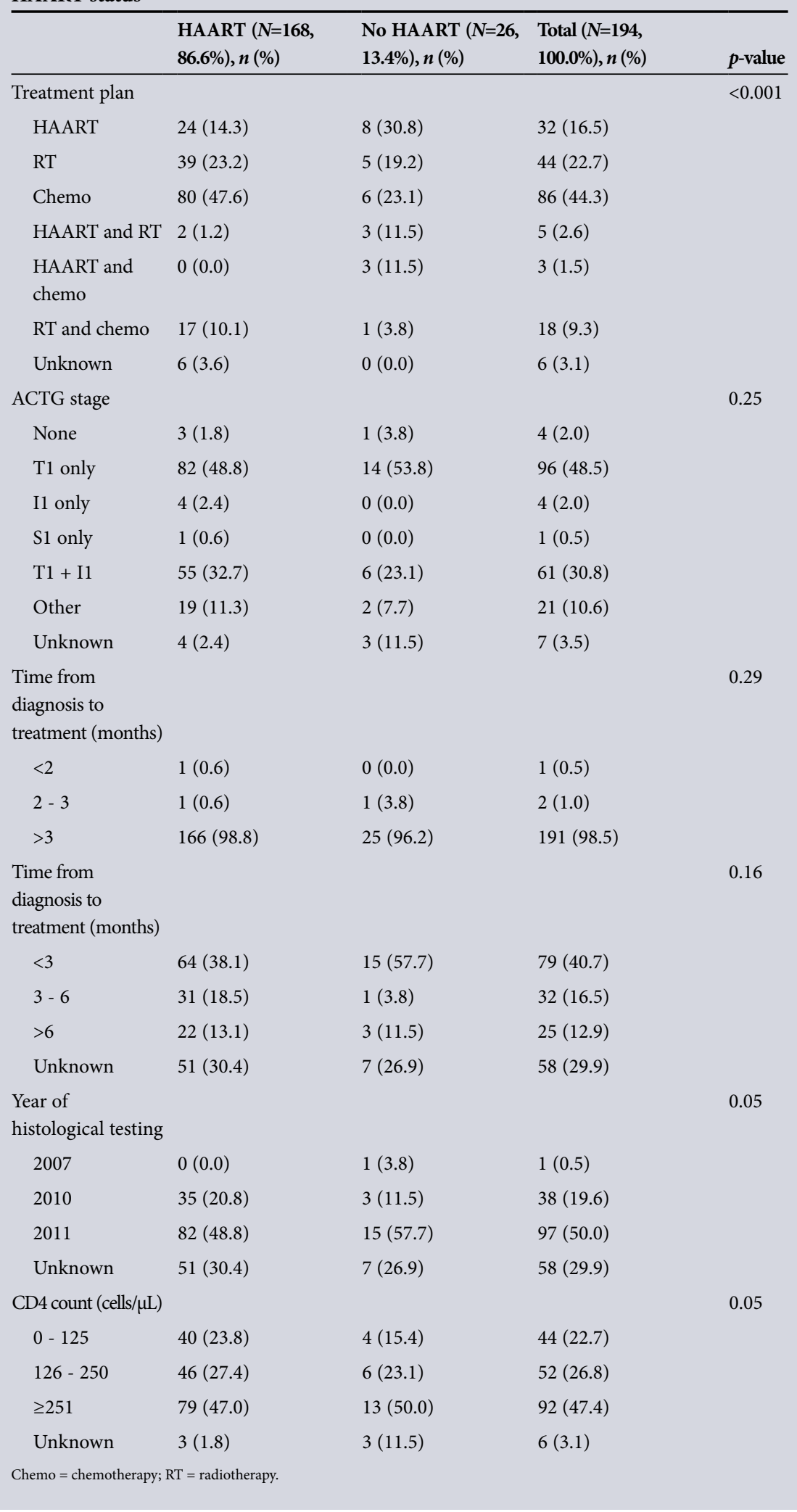

(78.9\%), but the difference in timeliness of presentation did not reach statistical significance $(p=0.09)$. The mean age at presentation was 36.6 (standard deviation (SD) 10.1) years. Females presented at a younger mean age than males, irrespective of HAART status, at 33.5 (SD 9.0) years v. 39.0 (SD 10.3) years $(p<0.001)$. Among patients on HAART, the mean age of females was 34.7 years and that of males 39 years $(p=0.003)$.
Among patients who were HAART naive, the mean age of females was 23.7 years while that of males was 39 years $(p=0.003)$. Males and patients on HAART were half as likely as females and patients not on HAART to present before their 30th birthday $(p=0.03)$ (Table 2).

Patients who were HAART naive were more likely than those on HAART to reside in urban areas $(80.8 \%$ v. $57.1 \%)$, but the difference did not reach statistical significance. Receiving HAART was not associated with extent of skin involvement, oral involvement, lymphoedema, fungating lesions or ulceration. However, HAARTnaive patients were three times as likely as those receiving HAART to have visceral involvement $(15.4 \%$ v. $4.8 \%) \quad(p=0.03)$. Opportunistic infections were mentioned in the charts of 25 of 194 patients. Of the 24 who were diagnosed with tuberculosis (TB), all but one was receiving HAART.

Rural residents had higher CD4 counts than urban residents; they were also marginally more recently diagnosed and more likely to have been seen in the oncology clinic $<3$ months after being diagnosed, but did not differ from urban residents in other respects (Table 3). In multivariate logistic regression analysis models that included CD4 count, age and gender, only age was associated with receiving HAART; patients aged $\geq 30$ years were more than three times as likely to receive HAART as younger patients (Table 4). In a similar model, also including age and gender, residents of rural areas were more than three times as likely to receive HAART as residents of urban areas (Table 5).

\section{Discussion}

Among $194 \mathrm{KS}$ patients seen in the ADH oncology clinic, nearly $87 \%$ were currently receiving HAART. In our multivariate models, which included gender, CD4 count, and treatment delay, only older age $(\geq 30$ years) and rural residence were associated with receiving HAART.

For nearly a decade prior to 2003 , the SA government's AIDS denialist stance and lack of willingness to authorise and implement an antiretroviral programme contributed to high rates of $\mathrm{HIV} /$ AIDS-related morbidity and mortality. During that period, the incidence of KS increased ${ }^{[9,12,13]}$ and HIV-KS patients had a dismal 2-year survival rate of $20 \%{ }^{[14]}$ Studies in Africa in the pre-HAART period repeatedly indicated a poorer disease profile in females than in males. ${ }^{[3]}$ Prior to the AIDS epidemic, KS had been a predominantly male disease in Africa. This pattern also prevailed in North 
Table 2. Age group and CD4 count group according to HAART status, stratified by gender

\begin{tabular}{|c|c|c|c|c|}
\hline & $\begin{array}{l}\text { HAART, } \\
n(\%)\end{array}$ & $\begin{array}{l}\text { No HAART, } \\
n(\%)\end{array}$ & $\begin{array}{l}\text { Total, } \\
n(\%)\end{array}$ & $p$-value \\
\hline Males & $92(84.4)$ & $17(15.6)$ & $109(100.0)$ & \\
\hline Age quartiles (years) & & & & 0.26 \\
\hline $2-29$ & $13(14.1)$ & $5(29.4)$ & $18(16.5)$ & \\
\hline $30-35$ & $22(23.9)$ & $2(11.8)$ & $24(22.0)$ & \\
\hline $36-41$ & $27(29.3)$ & $3(17.6)$ & $30(27.5)$ & \\
\hline $42-81$ & $30(32.6)$ & $7(41.2)$ & $37(33.9)$ & \\
\hline CD 4 count $($ cells $/ \mu \mathrm{L})$ & & & & 0.39 \\
\hline $0-125$ & $22(23.9)$ & $4(23.5)$ & $26(23.9)$ & \\
\hline $126-250$ & $27(29.3)$ & $3(17.6)$ & $30(27.5)$ & \\
\hline$\geq 251$ & $40(43.5)$ & $8(47.1)$ & $48(44.0)$ & \\
\hline Unknown & $3(3.3)$ & $2(11.8)$ & $5(4.6)$ & \\
\hline $\begin{array}{l}\text { Time from diagnosis to treatment } \\
\text { (months) }\end{array}$ & & & & 0.43 \\
\hline$<3$ & $37(40.2)$ & $9(52.9)$ & $46(42.2)$ & \\
\hline $3-6$ & $17(18.5)$ & $1(5.9)$ & $18(16.5)$ & \\
\hline$>6$ & $12(13.0)$ & $1(5.9)$ & $13(11.9)$ & \\
\hline Unknown & $26(28.3)$ & $6(35.3)$ & $32(29.4)$ & \\
\hline Females & $76(89.4)$ & $9(10.6)$ & $85(100.0)$ & \\
\hline Age quartiles (years) & & & & 0.03 \\
\hline $2-29$ & $23(30.3)$ & $7(77.8)$ & $30(35.3)$ & \\
\hline $30-35$ & $19(25.0)$ & $2(22.2)$ & $21(24.7)$ & \\
\hline $36-41$ & $23(30.3)$ & $0(0.0)$ & $23(27.1)$ & \\
\hline $42-81$ & $11(14.5)$ & $0(0.0)$ & $11(12.9)$ & \\
\hline CD 4 count $($ cells $/ \mu \mathrm{L})$ & & & & 0.01 \\
\hline $0-125$ & $18(23.7)$ & $0(0.0)$ & $18(21.2)$ & \\
\hline $126-250$ & $19(25.0)$ & $3(33.3)$ & $22(25.9)$ & \\
\hline$\geq 251$ & $39(51.3)$ & $5(55.6)$ & $44(51.8)$ & \\
\hline Unknown & $0(0.0)$ & $1(11.1)$ & $1(1.2)$ & \\
\hline $\begin{array}{l}\text { Time from diagnosis to treatment } \\
\text { (months) }\end{array}$ & & & & 0.15 \\
\hline$<3$ & 27 (35.5) & $6(66.7)$ & $33(38.8)$ & \\
\hline $3-6$ & $14(18.4)$ & $0(0.0)$ & $14(16.5)$ & \\
\hline$>6$ & $10(13.2)$ & $2(22.2)$ & $12(14.1)$ & \\
\hline Unknown & $25(32.9)$ & $1(11.1)$ & $26(30.6)$ & \\
\hline
\end{tabular}

America and Europe. However, in Africa the male/female ratio was not as high, and females with HIV-KS had an earlier age at presentation, more extensive cutaneous involvement, more advanced tumour stage, more systemic symptoms, a greater frequency of opportunistic infections and a poorer prognosis than males. ${ }^{[2,3,13]}$

The national HAART roll-out programme began in SA in 2003. An early chart study of KS patients seen at the ADH oncology clinic in 2004 - 2006 showed that $44 \%$ had received HAART, and mean CD4 counts rose from 200 cells $/ \mu \mathrm{L}(2001-2003)$ to 218 cells $/ \mu \mathrm{L}$ $(2004-2006) .{ }^{[9]}$
HAART alone with combined HAART and chemotherapy regimens among HIV-KS patients in SA, demonstrated that $39 \%$ of patients improved on HAART alone. The treatment arms did not differ with regard to virological load, CD4 count, KS stage, overall survival or quality of life.

The relative efficacy of HAART alone is encouraging for those in settings where resources are limited. Our voluntary counselling and testing (VCT) and antiretroviral enrolment programmes in KZN are improving, and with the plateau in our HIV epidemic, ${ }^{[16]}$ a decrease in both KS incidence and severity may still be hoped for with just HAART in hand.

In recent years, the $\mathrm{ADH}$ oncology clinic has adopted a requirement of VCT and establishment of HIV status prior to referral. As a result, all our study participants had had their HIV status established before they were referred to the clinic, compared with $86 \%$ in the preHAART era and $92 \%$ in the early HAART era. ${ }^{[9]}$ Moreover, the patients in the current study were nearly twice as likely to be receiving HAART as those seen at the same site in the early HAART period $^{[9]}$ and those in a more recent survey of the HIV population in general. ${ }^{[17]}$

The mean age at presentation of our study participants on HAART was 37 years, slightly older than the 32 - 36-year range of patients studied in the early HAART era. ${ }^{[9,13]}$ The mean CD4 count in this study was 266 cells $/ \mu \mathrm{L}$, higher than the previous CD4 count of 218 cells $/ \mu \mathrm{L}$ recorded in HIV-KS patients at this site..$^{[9]}$

Female patients with HIV-KS, whether or not they were on HAART, continued to present at a younger age than males (Table 2). The persistence of earlier age at presentation in females may reflect the persistence of the HIV burden among very young females; in a 2009 nationwide survey, females in the 15 - 24-year age group were more than three times as likely as males to be HIV-positive. The gender bias may even stronger in KZN, which has the highest HIV prevalence in SA; in a 2009 survey of pregnant women, the HIV prevalence was $39.5 \% .{ }^{[18]}$

In our sample, both HAART use and CD4 counts were in fact higher among females than among males, although the differences were not statistically significant (Table 2).

Recent studies in black African populations have found that females were more proactive than males in dealing with HIV, enrolling earlier and participating more broadly in HAART programmes. ${ }^{[1,20]}$

The finding that rural residents were more than three times as likely to use HAART as urban patients may reflect the successful implementation of national health policy to decentralise HAART initiation. It may also 
Table 3. Demographic and clinical factors according to rural/urban residence

\begin{tabular}{|c|c|c|c|c|}
\hline & $\begin{array}{l}\text { Urban } \\
(N=117,60.6 \%), \\
n(\%)\end{array}$ & $\begin{array}{l}\text { Rural } \\
(N=76,39.4 \%), \\
n(\%)\end{array}$ & $\begin{array}{l}\text { Total } \\
(N=193,100.0 \%) \\
n(\%)\end{array}$ & $p$-value \\
\hline Age quartiles (years) & & & & 0.24 \\
\hline $2-29$ & $29(24.8)$ & $19(25.0)$ & 48 (24.9) & \\
\hline $30-35$ & $32(27.4)$ & $13(17.1)$ & $45(23.3)$ & \\
\hline $36-41$ & $27(23.1)$ & $26(34.2)$ & $53(27.5)$ & \\
\hline $42-81$ & $29(24.8)$ & $18(23.7)$ & $47(24.4)$ & \\
\hline Gender & & & & 0.66 \\
\hline Male & $67(57.3)$ & $41(53.9)$ & $108(56.0)$ & \\
\hline Female & $50(42.7)$ & $35(46.1)$ & $85(44.0)$ & \\
\hline Oral lesions & & & & 0.33 \\
\hline Yes & $36(30.8)$ & $18(23.7)$ & $54(28.0)$ & \\
\hline No & $81(69.2)$ & $58(76.3)$ & $139(72.0)$ & \\
\hline Visceral lesions & & & & 0.29 \\
\hline Yes & $9(7.7)$ & $3(3.9)$ & $12(6.2)$ & \\
\hline No & $106(90.6)$ & $73(96.1)$ & $179(92.7)$ & \\
\hline Unknown & $2(1.7)$ & $0(0.0)$ & $2(1.0)$ & \\
\hline Lymphoedema & & & & 0.12 \\
\hline Yes & $52(44.4)$ & $39(51.3)$ & $91(47.2)$ & \\
\hline No & $64(54.7)$ & $35(46.1)$ & $99(51.3)$ & \\
\hline Unknown & $0(0.0)$ & $2(2.6)$ & $2(1.0)$ & \\
\hline Fungating lesions & & & & 0.20 \\
\hline Yes & $18(15.4)$ & $10(13.2)$ & $28(14.5)$ & \\
\hline No & $98(83.8)$ & $64(84.2)$ & $162(83.9)$ & \\
\hline Unknown & $0(0.0)$ & $2(2.6)$ & $2(1.0)$ & \\
\hline Ulceration & & & & 0.28 \\
\hline Yes & $7(6.0)$ & $2(2.6)$ & $9(4.7)$ & \\
\hline No & $108(92.3)$ & $74(97.4)$ & $182(94.3)$ & \\
\hline Unknown & $2(1.7)$ & $0(0.0)$ & $2(1.0)$ & \\
\hline $\begin{array}{l}\text { Time from diagnosis to } \\
\text { treatment (months) }\end{array}$ & & & & 0.06 \\
\hline$<3$ & $46(39.3)$ & $33(43.4)$ & $79(40.9)$ & \\
\hline $3-6$ & $16(13.7)$ & $16(21.1)$ & $32(16.6)$ & \\
\hline$>6$ & $12(10.3)$ & $12(15.8)$ & $24(12.4)$ & \\
\hline Unknown & $43(36.8)$ & 15 (19.7) & $58(30.1)$ & \\
\hline $\begin{array}{l}\text { Year of histological } \\
\text { examination }\end{array}$ & & & & 0.06 \\
\hline 2007 & $1(0.9)$ & $0(0.0)$ & $1(0.5)$ & \\
\hline 2010 & $19(16.2)$ & $18(23.7)$ & $37(19.2)$ & \\
\hline 2011 & $54(46.2)$ & $43(56.6)$ & $97(50.3)$ & \\
\hline Unknown & $43(36.8)$ & $15(19.7)$ & $58(30.1)$ & \\
\hline CD4 count $($ cells $/ \mu \mathrm{L})$ & & & & 0.04 \\
\hline $0-125$ & $33(28.2)$ & $11(14.5)$ & $44(22.8)$ & \\
\hline $126-250$ & $32(27.4)$ & $20(26.3)$ & $52(26.9)$ & \\
\hline$\geq 251$ & $47(40.2)$ & $44(57.9)$ & $91(47.2)$ & \\
\hline Unknown & $5(4.3)$ & $1(1.3)$ & $6(3.1)$ & \\
\hline
\end{tabular}

reflect self-selection by health-conscious or health-motivated individuals from rural areas who seek healthcare in an urban oncology clinic. Our sample may represent the tip of
Table 4. Association between receiving

HAART and CD4 count, age, and gender

\begin{tabular}{lcc}
\hline & OR & $\mathbf{9 5 \% ~ C I}$ \\
\hline CD4 count $(\mathrm{cells} / \mu \mathrm{L})$ & & \\
$0-125$ & 1.0 & Referent \\
$126-250$ & 0.6 & $0.2-2.4$ \\
$\geq 251$ & 0.5 & $0.2-1.8$ \\
Unknown & 0.1 & $0.0-0.9$
\end{tabular}

Age quartiles (years)

$\begin{array}{ccc}2-29 & 1.0 & \text { Referent } \\ 30-35 & 3.6 & 1.0-12.8 \\ 36-41 & 3.6 & 1.5-24.8 \\ 42-81 & 3.1 & 1.0-10.2 \\ \text { Gender } & & \\ \text { Male } & 1.0 & \text { Referent } \\ \text { Female } & 2.0 & 0.8-5.4\end{array}$

Table 5. Association between receiving HAART and rural/urban residence, age, and gender

\begin{tabular}{lcl}
\hline & OR & $\mathbf{9 5 \%} \mathbf{C I}$ \\
\hline Residence & & \\
$\quad$ Urban & 1.0 & Referent \\
Rural & 3.3 & $1.1-9.5$ \\
Age quartiles (years) & & \\
$2-29$ & 1.0 & Referent \\
$30-35$ & 4.8 & $1.3-17.3$ \\
$36-41$ & 6.3 & $1.6-25.3$ \\
$42-81$ & 3.3 & $0.9-8.4$ \\
Gender & & \\
Male & 1.0 & Referent \\
Female & 2.1 & $0.8-5.6$
\end{tabular}

an iceberg, floating above an HIV-KS patient population that is receiving either no care at all or sole care from traditional providers. We are currently developing a study to identify and address barriers to timely diagnosis and effective treatment of HIV-KS in KZN.

Most patients in the study presented at the oncology clinic $\geq 3$ months after histological diagnosis of KS. We were unable to determine how much of the delay was due to patients' reluctance to seek healthcare and how much to an overburdened healthcare system in which patients who actively seek care must wait months to receive it. Neither HAART nor location of residence was associated with extent of skin involvement, oral involvement, lymphoedema, fungating lesions or ulceration (data not shown). HAART-naive patients were, however, three times as likely to have visceral involvement as those receiving HAART $(15.4 \%$ v. $4.8 \%)(p=0.03)$. 


\section{Study limitations}

Our limited determination of associations should not lead to underestimation of the true value of HAART. Our sampling frame may have been affected by referral bias. Patients managed successfully for KS-related conditions at other healthcare facilities may not be represented in the sample that is eventually referred to the oncology clinic.

In addition, because the overwhelming majority of patients at the oncology site had advanced disease, we could not evaluate the effect of HAART use on tumour stage.

We also could not evaluate an association between HAART use and opportunistic infections. The most commonly documented infection among our patients was TB. The presentations of pulmonary TB and KS disseminated to the lung may be very similar in terms of respiratory tract signs and the presence of B symptoms (fever, loss of weight, fatigue). SA's high TB prevalence may prompt a diagnosis in favour of this disease without further investigation for HIV-KS. However, of 24 patients with TB in our sample, 23 were receiving HAART, and 20 had been diagnosed with TB before they presented at the oncology clinic. Further research is needed on the relationship between KS and TB and the true prevalence of dual pathology.

\section{Conclusion}

The use of HAART in SA has improved care for HIV-KS patients. In our sample, all patients had documented HIV status, and $86.6 \%$ had commenced HAART before their visit to the oncology clinic. Mean age at presentation has increased, both for the group as a whole and for females in particular. Mean CD4 cell counts have risen. If our sample is representative of the HIV-KS population in KZN, females are no longer shouldering a disproportionate burden of disease. Furthermore, the benefits of HAART appear to be equally distributed between the rural and urban settings. With HAART in hand, we have reason to hope that we can improve the lot of HIV-KS patients.

Funding. This research was supported by a short-term training fellowship of the Columbia University-Southern African Fogarty AIDS International Training and Research Programme, Fogarty International Centre, National Cancer Institute (grant D43 CA153715).

Authors' contributions. LN designed the study, collected information, analysed the data and wrote the manuscript. JSJ assisted in the study design, analysing the data and writing the manuscript. AM and AIN assisted in the study design and writing the manuscript, and NCD assisted in the study design.

\section{References}

1. Schwartz RA. Kaposi's sarcoma: Advances and perspectives. J Am Acad Dermatol 1996;34(5):804-814. DOI:10.1016/S0190-9622(96)90018-3

2. Mosam A, Hurkchand HP, Cassol E, et al. Characteristics of HIV-1-associated Kaposi's sarcoma among women and men in South Africa. Int J STD AIDS 2008;19(6):400-405. DOI:10.1258/ijsa.2008.007301 Meditz AL Borok M MaWhinney S, et al. Gender differences in AIDS-ass) 1258ted Kaposi in Harare Zimbabwe JAIDS I Acquir Immune Defic Syndr 2007:44(3):306-308. DOJ:10.1097/ in Harare, Zimbabwe. JAIDS J Acquir Immune Defic Syndr 2007:44(3):306-308. DOI:10.1097/ QAI.0b013e31802c83ds

Meir J, Francis N, et al. The effect of HAART in 254 consecutive patients with AIDS-related Kaposi's sarcoma. AIDS 2009;23(13):1701-1706. DOI:10.1097/QAD.0b013e32832d080d

5. Jacobson LP, Yamashita TE, Detels R, et al. Impact of potent antiretroviral therapy on the incidence of Kaposi's sarcoma and non-Hodgkin's lymphomas among HIV-1-infected individuals. JAIDS J Acquir Immune Defic Syndr 1999;21. http://journals.lww.com/jaids/Fulltext/1999/08011/Impact_of_Potent_ Antiretroviral_Therapy_on_the.8.aspx (accessed 11 May 2016).

6. Portsmouth S, Stebbing J, Gill J, et al. A comparison of regimens based on non-nucleoside reverse transcriptase inhibitors or protease inhibitors in preventing Kaposi's sarcoma. AIDS 2003;17(11):F17-F22.

7. Bower M, Fox P, Fife K, et al. Highly active anti-retroviral therapy (HAART) prolongs time to treatment failure in Kaposi sarcoma. AIDS 1999;13(15):2105-2111.

8. Stebbing J, Nelson M, Powles T, Gazzard B, Bower M. A prognostic index for AIDS-associated Kaposi's sarcoma in the era of highly active antiretroviral therapy. Lancet 2006;367(9521):1495-1502. DOI:10.1016/S0140-6736(06)68649-2

9. Mosam A, Shaik F Uldrick T Berkman A, Aboobaker J, Coovadia HM. Increasing incidence of Kaposi's sarcoma in black South Africans in KwaZulu-Natal, South Africa (1983-2006). Int J STD AIDS 2009:20(8):553-556. DOI:10.1258/ijsa.2008.008372

10. Mosam A, Uldrick TS, Shaik F, et al. An evaluation of the early effects of a combination antiretroviral therapy programme on the management of AIDS-associated Kaposi's sarcoma in KwaZulu-Natal, South Africa. Int J STD AIDS 2011;22(11):671-673. DOI:10.1258/ijsa.2009.00914

11. Krown SE, Testa MA, Huang J. AIDS-related Kaposi's sarcoma: Prospective validation of the AIDS Clinical Trials Group staging classification. AIDS Clinical Trials Group Oncology Committee. J Clin Oncol 1997;15(9):3085-3092.

12. Parkin DM WH, Nambooze S, Wabwire-Mangen F. AIDS-related cancers in Africa: Maturation of the epidemic in Uganda. AIDS 1999;13(18):2563-2570.

13. Phipps W, Nguyen H, Saracino M, et al. Gender differences in clinical presentation and outcomes of epidemic Kaposi sarcoma in Uganda. PLoS One 2010;5(11):e13936. DOI:10.1371/journal.pone. 0013936

14. Olweny CLM, Borok M, Gudza I, et al. Treatment of AIDS-associated Kaposi's sarcoma in Zimbabwe: Results of a randomized quality of life focused clinical trial. Int J Cancer 2005;113(4):632-629. DOI:10.1002/ijc.20606

15. Mosam A, Shaik F, Uldrick TS, et al. A randomized controlled trial of HAART versus HAART and chemotherapy in therapy-naive patients with HIV-associated Kaposi sarcoma in South Africa. JAIDS I Acquir Immune Defic Syndr 2012;60(2):150-157. DOI:10.1097/QAI.0b013e318251aedd

16. Statistics South Africa. Mid-year Population Estimates, 2011. Pretoria: SSA, 2011. http://www.statssa. gov.za/publications/P0302/P03022011.pdf (accessed 4 May 2016).

17. United Nations. The Millenium Development Goals Report, 2010. United Nations, 2010. http:// www.un.org/millenniumgoals/pdf/MDG\%20Report\%202010\%20En\%20r15\%20-low\%20res\%20 20100615\%20-pdf (accessed 4 May 2016).

18. UNAIDS. Global AIDS Response Progress Report 2012. http://www.unaids.org/sites/default/files/ country/documents//file,69086,es..pdf (accessed 4 May 2016).

19. Obermeyer CM, Sankarab A, Bastienb V, et al. Gender and HIV testing in Burkina Faso: An exploratory study. Soc Sci Med 2009;69(6):877-884. DOI:10.1016/j.socscimed.2009.07.003

20. Chirawu P, Mavhu W, Pascoe S, Dirawo J, Cowan F. Acceptability and challenges of implementing voluntary counselling and testing (VCT) in rural Zimbabwe: Evidence from the Regai Dzive Shiri Project. AIDS Care 2010;22(1):81-88. DOI:10.1080/09540120903012577

Accepted 23 November 2015 